\title{
Study on Vertical Dynamic Characteristics of Composite Sleeper Ballasted Track in Tunnels
}

\author{
ZHAO Zhenhang ${ }^{1, *}$, SHEN Yuting ${ }^{1}, Y^{\prime} A N X u e^{1}$, and SU Qiankun ${ }^{2}$ \\ ${ }^{1}$ MOE Key Laboratory of High-speed Railway Engineering, Southwest Jiaotong University, Chengdu 610031 \\ ${ }^{2}$ China Railway Eryuan Group ,Ltd, Chengdu 610031
}

\begin{abstract}
In order to study the vertical dynamic characteristics of the composite sleeper ballasted track in tunnels, this paper establishes a dynamic model based on the finite element method, and compares the dynamic response of vehicle, wheel and rail systems, track systems and backfill layer with the type-III concrete sleeper. The research results show that the composite sleeper ballasted tracks' acceleration of the car body and the wheel-rail force are smaller than that of the type-III sleeper. It can meet the safety of the train and passenger comfort. Because the composite sleeper has good elasticity, The rail displacement and acceleration, the sleeper displacement and acceleration of the composite sleeper are slightly larger than the type-III sleeper ballasted track, but the effect is not great. The composite sleeper has good elasticity and large damping, so that the acceleration of the track bed and the backfill layer is less than that of the type-III sleeper ballasted track. This shows that the composite sleeper has vibration damping characteristics for the track bed and the backfill layer.
\end{abstract}

With the rapidly development of China's railway industry, at present, China's high-speed railway has accounted for more than $60 \%$ of the world's railways. Most high-speed railways are ballastless tracks. However, in special areas, such as railway crossing seismic belts, it is necessary to consider ballasted track[1-2]. The used track is concrete sleeper ballasted track. At present, the composite sleeper is made of composite polymer materials such as waste tires and plastics, and glass fiber filaments are added to enhance the performance. The composite sleeper has the characteristics of good elasticity, light weight and vibration damping performance. The composite sleeper is rarely used in high-speed railways, and it is of great significance for its promotion and application.

Many scholars have studied the composite sleeper mainly for its material composition and static performance. In terms of materials, Chen Yuxi[3] carried out three parts experimental research on the preparation process, material composition and structural design optimization, and material properties of the new sleeper composite materials. According to the optimal solution of each experiment, the new sleeper composite components and their performance requirements were determined. its performance parameters. In terms of mechanical properties, Richard Lampo[4] measured the ultimate strength of the composite sleeper, the modulus of elasticity, and the pull-out resistance of the thread spikes, and analyzed the potential factors causing the track safety problem. Duan Haibin[5] studied the vertical dynamic characteristics of the composite sleeper ballasted track, and used the track bed thickness, fastener stiffness and sleeper spacing as the influencing parameters to optimize the composite sleeper ballasted track. Domestic and foreign composite sleeper ballasted track are mainly used in heavy-duty railways, and the application on high-speed railways is still blank.

In this paper, the dynamic characteristics of the composite sleeper ballasted track are studied, and the dynamic model is established to study the dynamic characteristics of the vehicle, track structure and foundation, and provide theoretical basis for its application.

\section{MECHANICAL MODEL}

A vehicle-track coupling dynamics model is established. In this model, the whole vehicle can be modeled as one with two suspensions, involving the upand-down and nodding movement of the vehicle body and bogies, and the vertical movement of four wheels, a total of 10 degrees of freedom (Figure 1).

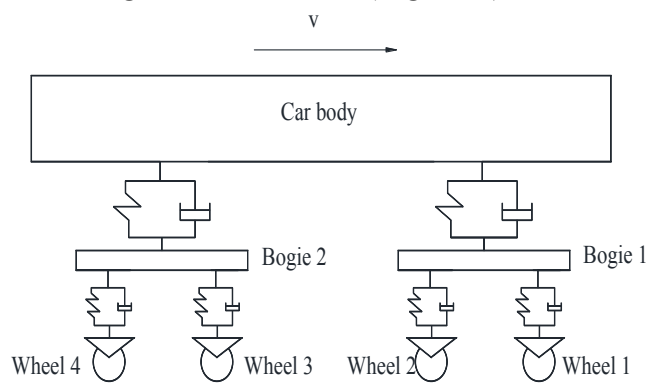

Fig. 1 Model of vehicle

Corresponding author: 250868445@qqu.com 
The track structure consists of rails, fasteners, sleepers and track beds. The rail is simplified to the Euler beam; the fastener is simulated by the spring damping unit; the sleeper is simulated by the beam unit; the ballast bed is discretely divided into rigid masses in the longitudinal direction, and the stiffness and damping are distributed to the upper and lower layers of the spring, adjacent masses The shear stiffness and shear damping of the track bed are introduced to simulate the longitudinal interaction of the ballast bed; the backfill layer in the tunnel is simplified as a plate element, and the mechanical model is shown in Figure 2:

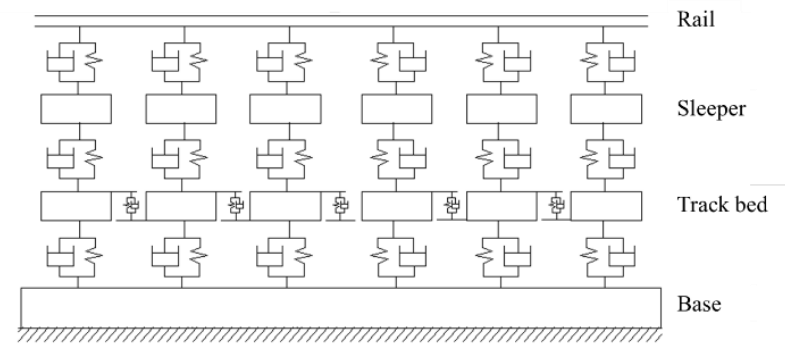

Fig. 2 Mechanical model of track structure

The vertical coupling between the vehicle and the track subsystem is realized by the wheel-rail contact interface. Considering the Hertz linear contact, the track irregularity excitation selects the German high-speed low-interference spectrum that meets the actual vehicle operating conditions.

The elastic modulus of the composite sleeper is $1723 \mathrm{MPa}$, the Poisson's ratio is 0.3 , and the length, width and height are $2.7 \mathrm{~m}, 0.22 \mathrm{~m}$ and $0.18 \mathrm{~m}$, respectively. Other track structural parameters are referenced [6].

\section{ANALYSIS OF CALCULATION RESULTS}

In order to compare and analyze the dynamic characteristics of the composite sleep ballasted track, the dynamic characteristics of the type-III concrete sleeper are also calculated. The vehicle speed in the model is $250 \mathrm{~km} / \mathrm{h}$

\subsection{Vehicle dynamic response}

The acceleration of the car body is shown in Figure 3. It can be seen from the figure that the acceleration of the car body under the composite sleeper structure is $0.0398 \mathrm{~m} / \mathrm{s}^{2}$, which is slightly larger than the $0.0297 \mathrm{~m} / \mathrm{s}^{2}$ of the type-III concrete sleeper. According to the regulations of China's high-speed railway, the vertical acceleration of the car body is not more than 0.13. g, therefore, the composite sleeper ballasted track meet the requirements of stability and comfort.

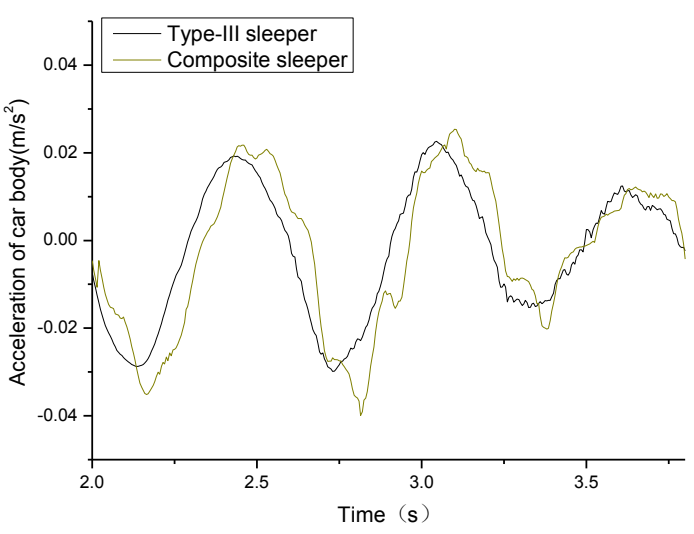

Fig. 3 Acceleration of car body

\subsection{Wheel-rail system dynamic response}

The vertical force of the wheel and rail is shown in Figure 4. It can be seen from the figure that the vertical forces of the two rails are not much different. The maximum vertical forces of the composite sleeper and the type-III sleeper are $103.5 \mathrm{kN}$ and $99.01 \mathrm{kN}$ respectively. The wheel load shedding are 0.414 and 0.439 respectively. It can be seen that the wheel-rail force is less than the limit of $170 \mathrm{kN}$, and the wheel load shedding rate is less than the limit of 0.6 .

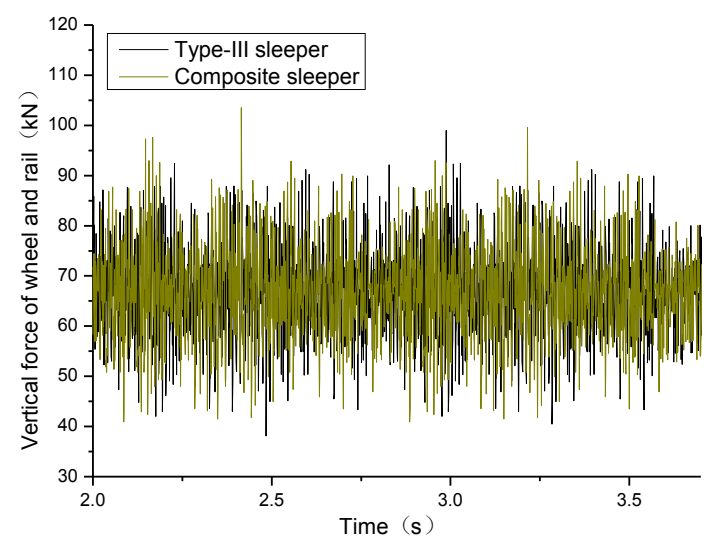

Fig. 4 Vertical force of wheel and rail

\subsection{Track system dynamic response}

Figure 5 and Figure 6 show the displacement and acceleration of the two tracks. The maximum rail vertical displacement of the composite sleeper ballasted track is $1.07 \mathrm{~mm}$, which is slightly larger than the $0.78 \mathrm{~mm}$ of the type-III sleeper ballasted track. This also shows that the composite sleepers have better elasticity, the displacement is larger under the load; the peak acceleration of the composite sleeper ballasted track's rail is $916.01 \mathrm{~m} / \mathrm{s} 2$, which is larger than the $899.99 \mathrm{~m} / \mathrm{s} 2$ of the type-III sleeper rail. The composite sleeper has elasticity, which can slightly increase the upper rail. vibration. 


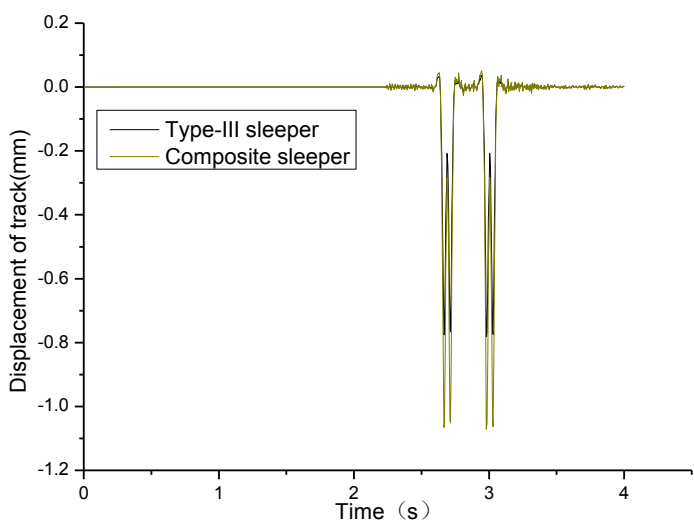

Fig. 5 Displacement of track

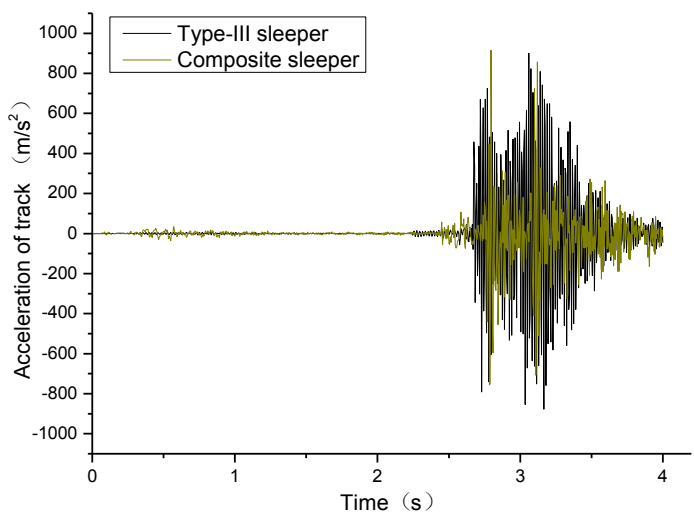

Fig. 6 Acceleration of track

Figure 7 and Figure 8 show the displacement and acceleration of the two track sleepers. The maximum vertical displacement of the composite sleeper is $0.41 \mathrm{~mm}$, which is greater than the $0.23 \mathrm{~mm}$ of type-III sleeper. This is inextricably related to the composite sleeper elasticity; The peak acceleration of the track sleeper with the track sleeper is $38.93 \mathrm{~m} / \mathrm{s} 2$, which is slightly larger than the $37.5 \mathrm{~m} / \mathrm{s} 2$ of the III sleeper.

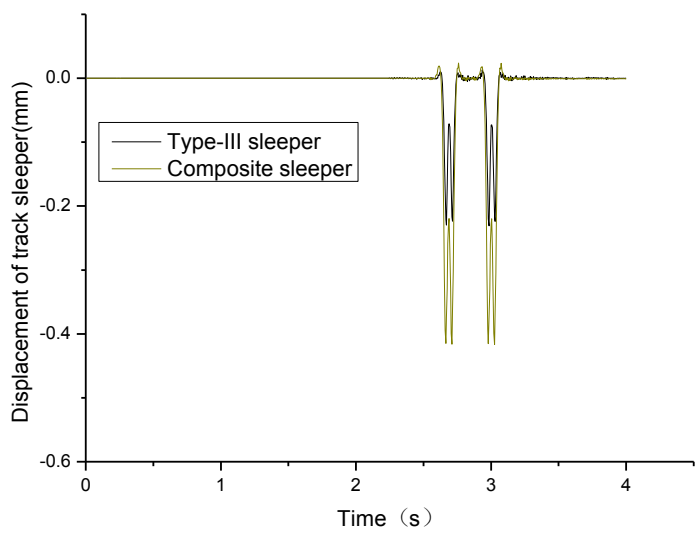

Fig. 7 Displacement of track sleeper

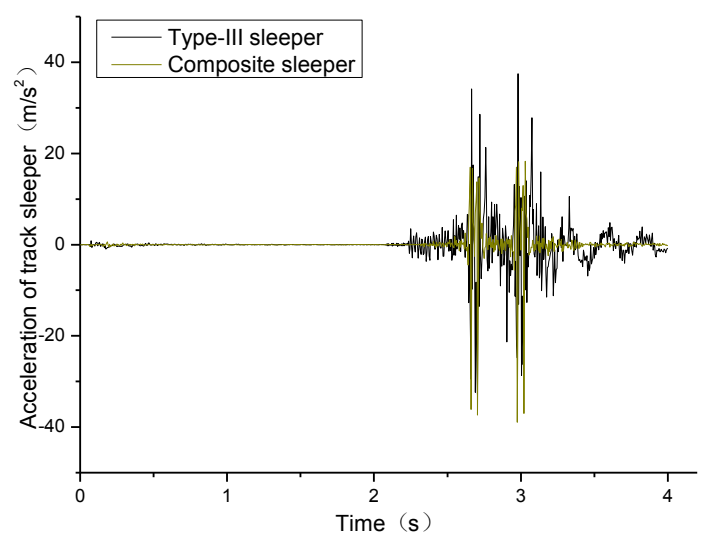

Fig. 8 Acceleration of track sleeper

Figure 9 and Figure 10 show the displacement and acceleration of the two track beds. The maximum bed vertical displacement of the composite sleeper ballasted track is $0.116 \mathrm{~mm}$, which is slightly smaller than the $0.121 \mathrm{~mm}$ of the type-III sleeper ballasted track. The composite sleeper has better elasticity and the load is transmitted more evenly. Therefore, the maximum displacement of the track bed is slightly smaller. the peak acceleration of the composite sleeper ballasted track's bed is $7.57 \mathrm{~m} / \mathrm{s} 2$, which is smaller than the $8.9 \mathrm{~m} / \mathrm{s} 2$ of the type-III sleeper. The composite sleeper ballasted track bed has a damping effect.

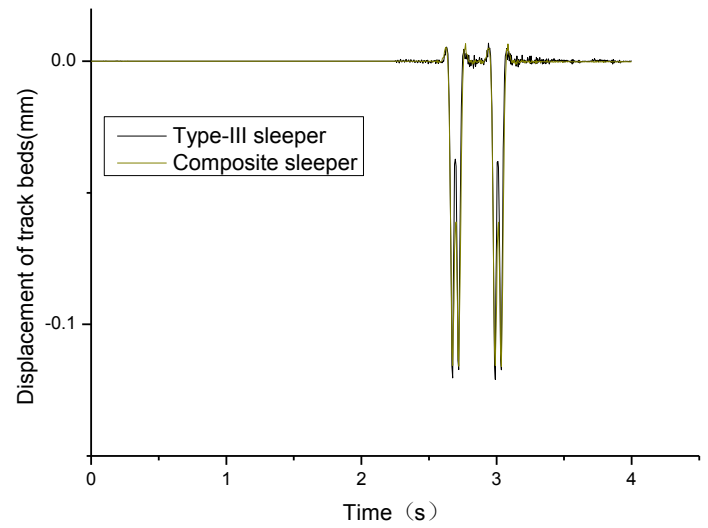

Fig. 9 Displacement of track beds

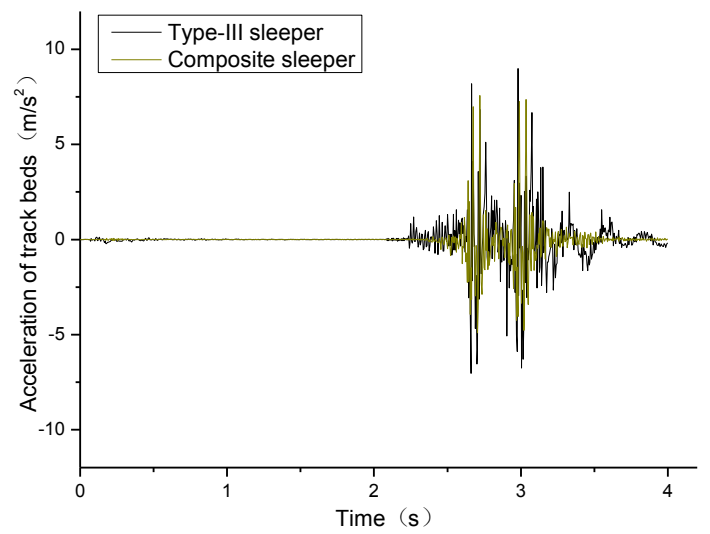


Fig. 10 Acceleration of track beds

\subsection{Backfill dynamic response}

Figure 11 shows the acceleration of the two track backfill layer. The maximum backfill layer acceleration of the composite sleeper ballasted track is $0.186 \mathrm{~m} / \mathrm{s} 2$, which is smaller than the $0.277 \mathrm{~m} / \mathrm{s} 2$ of the type-III sleeper ballasted track. The composite sleeper has a better damping effect for the backfill layer.

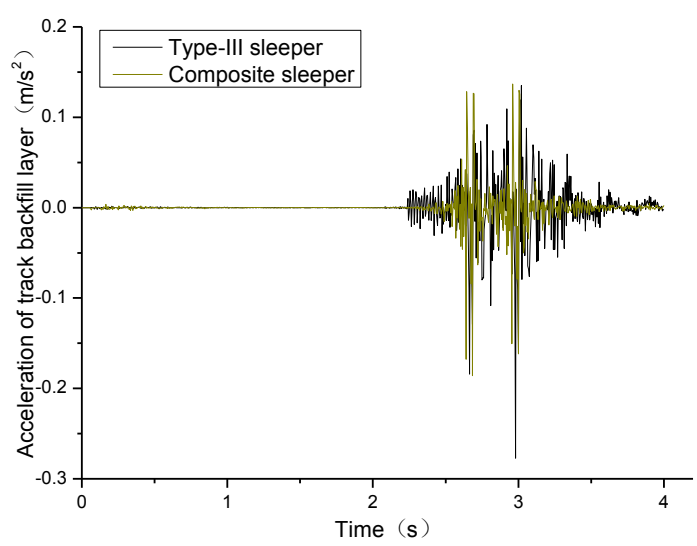

Fig. 11 Acceleration of track backfill layer

\section{CONCLUSION}

In this paper, the dynamic model is established. The type-III sleeper ballasted track is used as a comparison to analyze the dynamic characteristics of the composite sleeper ballasted track. The main conclusions are as follows:

(1) The acceleration of the body and the wheel-rail force of the composite sleeper ballasted track are smaller than that of the type-III sleeper ballasted track, which can meet the safety of the train and the comfort of the passenger;

(2) Due to the good elasticity of the composite sleeper, the rail displacement and acceleration, the sleeper displacement and acceleration of the composite sleeper ballasted track are slightly larger than the type-III sleeper ballasted track, but the impact is not significant;

(3) The composite sleeper has good elasticity and large damping, so the acceleration of the track bed and the backfill layer is smaller than that of the type-III sleeper ballasted track, indicating that the composite sleeper has damping characteristics for the track bed and the backfill layer.
1. Wang Ping.Modern Railway Track[M].Beijing: China Railway Press, 2014

2. Gao Liang.Track

Engineering[M].Chongqing:Chongqing University Press, 2014

3. Chen Yuxiao.The Study on the Structure and Composition of New Sleeper Composite Materials.Harbin: Northeast Forestry, 2008

4. Lampo R G, Nosker $\mathrm{T}$ J.Sullivan $\mathrm{H}$ W. Development testing and applications of recycled-plastic composite cross ties[C]//World congress on railway research, 2003

5. Duan Haibin. Study on the Vertical Dynamic Behavior of Recycled Plastic Composite Crosstie Ballast Structure [D].Chengdu : Southwest Jiaotong University, 2017.

6. Zhai Wanming.Vehicle-Track Coupled Dynamics[M].Beijing:Science Press, 2015

\section{References}

